\title{
Retrospective Autopsy Based Study of Fatal Road Traffic Accidents in Fiji
}

James JVP Kalougivaki ${ }^{\star *}$ and Ramaswamy PS Goundar²

${ }^{1}$ Forensic Pathology, Acting head, Forensic Science Service, Fiji Police Force, Fiji

${ }^{2}$ Pathology Department, Reader, Fiji National University, Fiji

\begin{abstract}
Objective: To describe the demographic profile and distribution of injuries from autopsy cases due to fatal Road Traffic Accidents (RTA) in Fiji.

Methods: This is a retrospective autopsy based study consisting of 102 medico-legal autopsies performed by the Fiji Institute of Forensic Science, Fiji Police Force during the period of two calendar years from January $1^{\text {st }} 2011$ to December 31 2012.

Results: Out of the 1454 medico-legal autopsies performed during the study period, $102(7 \%)$ were due to fatal RTA. There were $72(70.5 \%)$ males and $30(29.5 \%)$ female fatalities with an overall male and female ratio of 2.3:1 and the 30 to 44 years age group showed highest number of victims of $30(29.4 \%)$. The months of October in 2011 and August in 2012 took the maximum toll of road traffic deaths of $9(8.8 \%)$ and $12(11.6 \%)$ respectively. The highest number within the road user group were the passengers of $53(51.9 \%)$ followed by the pedestrians and drivers of $32(31.2 \%)$ and $16(15.6 \%)$ respectively. Human behavioural errors or factors by all the road users of $95(93.1 \%)$ was the highest contributing factor and pre-hospital mortality was most common, particularly road traffic death at the scene $(51.9 \%)$ and those whilst en route to hospital $(29.4 \%)$. Highest number of injuries were head injuries of 67 $(65.7 \%)$, followed by multiple injuries of $57(55.6 \%)$, thoracic injuries of $56(54.9 \%)$, abdominal injuries of $31(30.3 \%)$, vertebral injuries $21(20.5 \%)$ and major vessel injuries of $12(11.7 \%)$. The most common mechanism of death was haemorrhagic shock of $90(88.2 \%)$ followed by asphyxia of $7(6.8 \%)$, arrhythmias of $3(2.9 \%)$ and finally septic shock of $2(1.9 \%)$.

Conclusion: This study emphasizes the need for better pre-hospital and hospital trauma management, improved traffic law enforcement, effective traffic related and health policy creation, and the establishment of a national traffic traumatic injury surveillance registry in Fiji.
\end{abstract}

Keywords: Fiji; Autopsy; Road traffic accidents; Fracture; Head injury

\section{Introduction}

Road Traffic Accidents (RTA) accounts for $1.7 \%$ of global mortality and $91 \%$ of the world's fatalities on the roads occur in the low-income and middle-income countries [1]. In middle-income and developing countries like Fiji, the costs incurred as a result of RTA account for 3 to $5 \%$ of the gross domestic product [2]. Furthermore, RTA are considered part of the "diseases of development" and occur as a result of third world development components that include the increase in the number of motor vehicles, environmental changes, increased population densities and pollution $[3,4]$. The average population growth rate in Fiji is $0.8 \%$ [5] with the recorded total population of 837271 in 2007 [6] and 874700 in 2012 [5]. There has been a constant growth of the number of motor vehicles in Fiji from 185 (2007) to 199 (2012) per 1000 population [6]. The majority of motor vehicles in Fiji are four wheeled whilst the two wheeled vehicles account for $2.9 \%$ of all vehicles [6]. Fiji has a number of measures enforced by the Land Transport Authority to ensure road safety. These measures include demerit point system, appropriate road type speed limits and laws on drink-driving, seat-belt, child restraint, mobile phones used whilst driving and motorcyclist not wearing helmets [7]. The raw surveillance of RTA is carried out by Traffic Control Division of the Fiji Police Force. Accordingly, the survey of the RTA from 2010 to 2013 showed that on average 5.2 RTA occur daily and there was a road traffic death rate of 5.7 per 100000 population occurring annually in Fiji.

\section{Objective}

Therefore, the aim of this study is to describe the demographic profile and distribution of injuries from autopsy cases due to fatal RTA.

This in turn, can be used for public awareness on road safety and aid the improvement of emergency services in response to road traffic accidents in Fiji. Particularly, improving the transportation of those post-crash seriously injured via ambulances which occurs in $10 \%$ of RTA in Fiji [7].

\section{Materials and Methods}

This is a retrospective autopsy based study consisting of 102 medico-legal autopsies performed by the Fiji institute of Forensic Science, Fiji Police Force during the period of two calendar years from January $1^{\text {st }} 2011$ to December $31^{\text {st }} 2012$. The detailed analysis of these cases was based on the situation or inquest reports, investigation officer's accounts, medical records and evaluation of autopsy reports.

There was a detailed proforma prepared to capture and record the epidemiological data and details of injuries sustained etc. and the observations were thereafter statistically analyzed.

*Corresponding author: James JVP Kalougivaki, Acting head, Forensic Pathology, Forensic Science Service, Fiji Police Force, Fiji, Tel: +679 9905601 ; E-mail: james.kalougivaki@gmail.com

Received October 08, 2014; Accepted October 14, 2014; Published October 24 2014

Citation: Kalougivaki JJVP, Goundar RPS (2014) Retrospective Autopsy Based Study of Fatal Road Traffic Accidents in Fiji. J Forensic Res 5: 243 doi:10.4172/2157-7145.1000243

Copyright: (C) 2014 Kalougivaki JJVP, et al. This is an open-access article distributed under the terms of the Creative Commons Attribution License, which permits unrestricted use, distribution, and reproduction in any medium, provided the original author and source are credited. 


\section{Observations and Results}

Out of the 1454 medico-legal autopsies performed during the study period, 102 (7\%) were due to fatal RTA (Figure 1) accordingly. The 30 to 44 years age group showed highest number of victims of $30(29.4 \%)$ and also had the maximum gender differentiation with a male and female ratio of $4: 1$. This was followed by the age groups 45 to 59 years of $27(26.4 \%)$ and 15 to 29 years of $23(22.5 \%)$ and with both age groups having a male to female ratio of 2.3:1 (Table 1). The months of October in 2011 and August in 2012 showed the highest number of fatal RTA of $9(8.8 \%)$ and $12(11.6 \%)$ respectively (Figure 2$)$. The Fijians of Indian descent ethnic group had 51 (50\%) of the road traffic deaths whilst the iTaukei (Indigenous) group had 47 (46\%) (Figure 3a). There were 72 (70.5\%) males and $30(29.5 \%)$ female fatalities with an overall male and female ratio of 2.3:1 where males fully outnumber the female group.

The highest number within the road user group were the passengers of $53(51.9 \%)$ followed by the pedestrians and drivers of $32(31.2 \%)$ and 16 (15.6\%) respectively (Table 2 ).

Human behavioural errors or factors by the road users of 95 (93.1\%) was the highest contributing factor followed by environmental and machine factors respectively (Table 3 ). Vehicle-vehicle collision was the commonest type of fatal road traffic accident collision causing death of $48(47 \%)$ followed by those hit by light goods vehicle (taxi, private car, jeep, van etc.) of $24(23.5 \%)$ (Table 4$)$. The national divisions

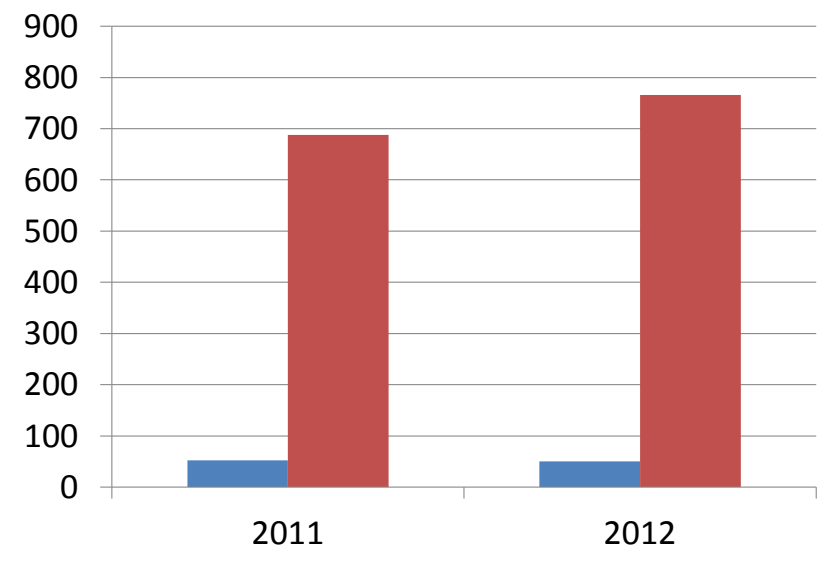

Figure 1: Annual distribution of total medico-legal cases for autopsies (Red bar) and the fatal road traffic accident autopsy cases (Blue bar).

\begin{tabular}{|l|c|c|c|}
\hline Age group & Male & Female & M: F ratio \\
\hline A (0 to 14 years) & 7 & 5 & $1.5: 1$ \\
\hline B (15 to 29 years) & 16 & 7 & $2.3: 1$ \\
\hline C (30 to 44 years) & 24 & 6 & $4: 1$ \\
\hline D (45 to 59 years) & 19 & 8 & $2.3: 1$ \\
\hline E (> 60 years) & 6 & 4 & $1.5: 1$ \\
\hline Total & $72(70.5 \%)$ & $30(29.5 \%)$ & $2.3: 1$ \\
\hline
\end{tabular}

Table 1: Age and gender distribution of road traffic deaths.

\begin{tabular}{|l|c|c|}
\hline Road user & $\mathbf{n = 1 0 2}$ & Percentage victims \\
\hline Driver & 16 & 15.6 \\
\hline Pedestrian & 32 & 31.2 \\
\hline Passenger & 53 & 51.9 \\
\hline Bicyclist & 1 & 0.9 \\
\hline
\end{tabular}

Table 2: Road user distribution of road traffic deaths.

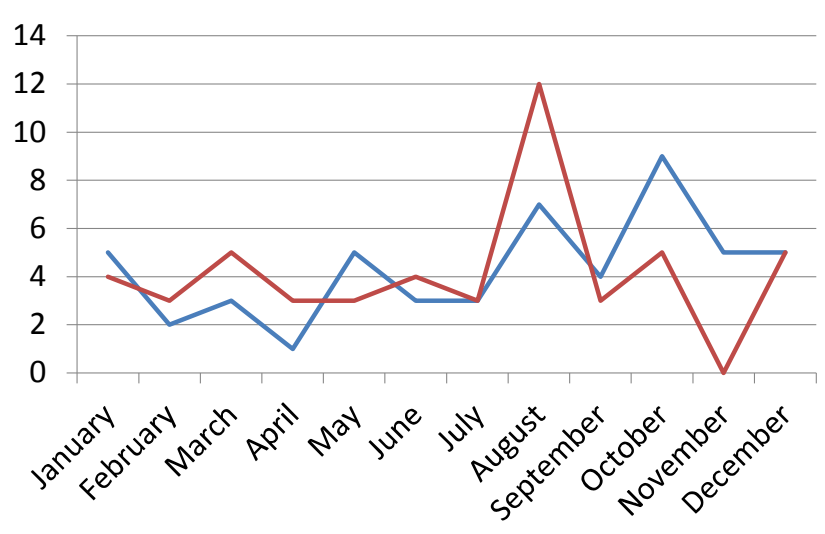

Figure 2: Distribution of fatal road traffic accidents according to month for the year 2011 (Blue bar) and 2012 (Red bar).

Human behavioural errors or factors by the road users of $95(93.1 \%)$ was the highest contributing factor followed by environmental and machine factors respectively (Table 3 ). Vehicle-vehicle collision was the commonest type of fatal road traffic accident collision causing death of $48(47 \%)$ followed by those hit by light goods vehicle (taxi, private car, jeep, van etc.) of 24 $(23.5 \%)$ (Table 5). The national divisions having the most road traffic deaths were the Western of $52(50.9 \%)$ and Central of $41(40.1 \%)$. Majority of fatal RTA of $41(40.1 \%)$ occurred on semi-urban roads and followed by those occurring on the highway of $26(25.4 \%)$ and rural roads of $23(22.5 \%)$ (Table 6 ). Most of road traffic deaths of $53(51.9 \%)$ were immediate at the scene of the accident whilst $30(29.4 \%)$ were en route to hospital and $18(17.6 \%)$ were at the hospital (Figure 3).

\begin{tabular}{|l|c|c|}
\hline Contributing factor or error & $\mathbf{n = 1 0 2}$ & Percentage victims \\
\hline Human behavioural & 95 & 93.1 \\
\hline Machine & 4 & 3.9 \\
\hline Environmental & 6 & 5.8 \\
\hline
\end{tabular}

Table 3: Contributing factors or errors to fatal road traffic accidents.

\begin{tabular}{|l|c|c|}
\hline Type of collision & $\mathbf{n = 1 0 2}$ & Percentage victims \\
\hline Vehicle-vehicle collision & 48 & 47 \\
\hline Hit by light goods vehicle & 24 & 23.5 \\
\hline Hit by bus & 2 & 1.9 \\
\hline Hit by truck & 1 & 0.9 \\
\hline Off road and overturned & 14 & 13.7 \\
\hline Runover by light goods vehicle & 2 & 1.9 \\
\hline Runover by bus & 1 & 0.9 \\
\hline Runover by tractor & 1 & 0.9 \\
\hline Vehicle-object collision & 8 & 7.8 \\
\hline Vehicle-parked vehicle collision & 1 & 0.9 \\
\hline
\end{tabular}

Table 4: Type of fatal road traffic accident collision causing death.

\begin{tabular}{|l|c|c|c|}
\hline $\begin{array}{l}\text { National } \\
\text { divisions }\end{array}$ & $\mathbf{n = 1 0 2}$ & $\begin{array}{c}\text { Percentage } \\
\text { victims }\end{array}$ & $\begin{array}{c}\text { Divisional } \\
\text { population }\end{array}$ \\
\hline Western & 52 & 50.9 & $3,19,611$ \\
\hline Central & 41 & 40.1 & $3,42,386$ \\
\hline Northern & 9 & 8.8 & 37,311 \\
\hline Eastern & 0 & 0 & 37,311 \\
\hline
\end{tabular}

Table 5: Distribution of road traffic deaths according to national divisions.

having the most road traffic deaths were the Western of $52(50.9 \%)$ and Central of 41 (40.1\%) (Table 5). Majority of fatal RTA of 41 (40.1\%) occurred on semi-urban roads and followed by those occurring on the highway of $26(25.4 \%)$ and rural roads of 23 (22.5\%) (Table 6). Most of road traffic deaths of $53(51.9 \%)$ were immediate at the scene of the accident whilst $30(29.4 \%)$ were en route to hospital and $18(17.6 \%)$ were at the hospital (Figure $3 \mathrm{~b}$ ). 


\begin{tabular}{|l|c|c|}
\hline Type of road & $\mathbf{n = 1 0 2}$ & Percentage victims \\
\hline Highway & 26 & 25.4 \\
\hline Urban & 10 & 9.8 \\
\hline Semi-urban & 41 & 40.1 \\
\hline Rural & 23 & 22.5 \\
\hline Within the boundaries of a property & 2 & 1.9 \\
\hline
\end{tabular}

Table 6: Type of roads where fatal road traffic accidents occurred.
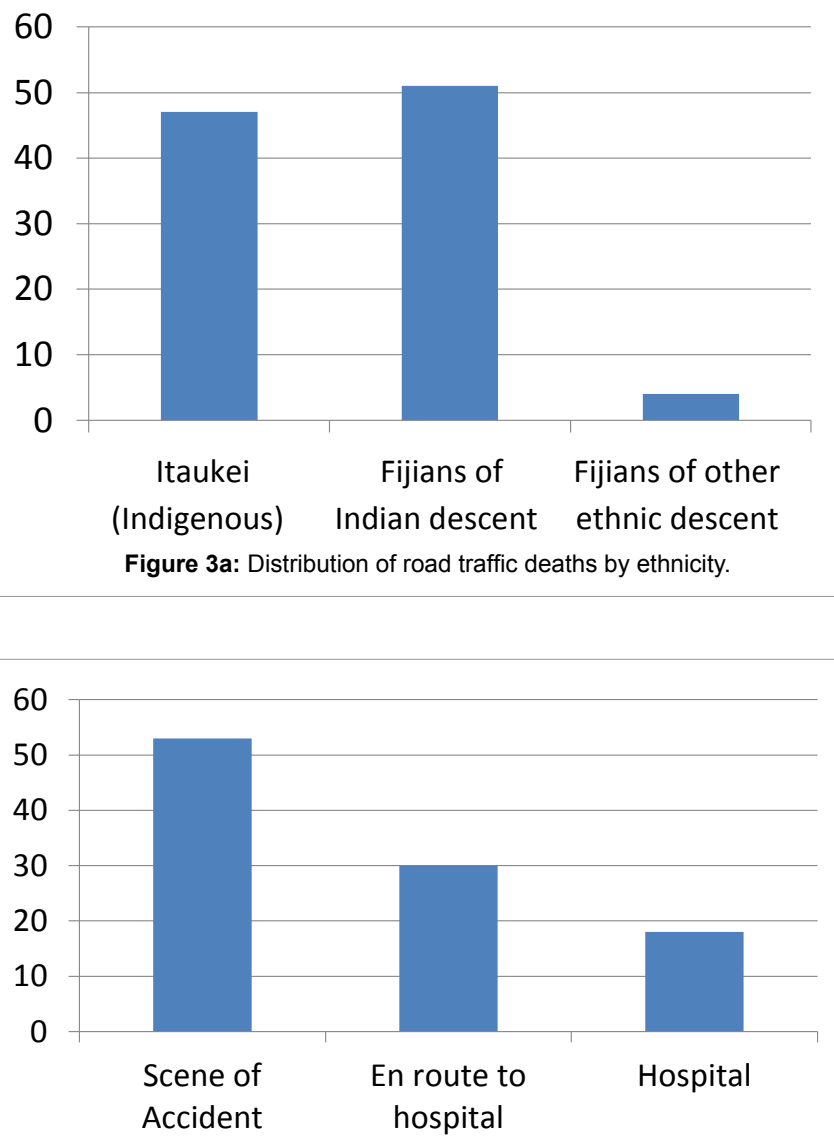

Figure 3b: Distribution of the place of road traffic deaths.

Out of the 18 road traffic deaths in hospital, 8 (44.4\%) died within the first 24 hours and 3 (16.7\%) died within the more than 24 hours to less than a week group, of which 2 had craniotomies and 1 had a laparotomy (Table 7).

\section{Distribution of injuries}

The highest number of injuries found was head injuries of 67 (65.7\%), followed by multiple injuries of $57(55.6 \%)$, thoracic injuries of $56(54.9 \%)$, abdominal injuries of 31 (30.3\%), vertebral injuries 21 (20.5\%) and vessel injuries of 12 (11.7\%) (Figure 4). Review of all the head injuries showed the commonest injuries were scalp injuries of 53 $(79.1 \%)$ followed by the life threatening intracranial haemorrhages of $42(41.1 \%)$, of which majority were subarachnoid of $36(85.7 \%)$ and subdural of $31(73.8 \%)$ (Table 8). The other head injuries were brain injury of 27 (40.2\%), subscapular haematomas of $26(38.8 \%)$ and torn meninges of $5(7.5 \%)$.There were 39 (58.2\%) head injuries with skull fractures and $28(41.8 \%)$ without skull fractures (Table 8 ).
Also important to note is that $14(33.3 \%)$ of all intracranial haemorrhages were found without fractures (Table 9). Out of the 39 (58.2\%) that had skull fractures the commonest type of fracture was comminuted of $18(46.2 \%)$ followed by linear and base of skull fractures of $15(38.4 \%)$ respectively (Table 10$)$. The skull bones commonly fractured were the temporal of $20(51.2 \%)$, frontal of 16 (41\%), parietal of $10(25.6 \%)$ and with regards to base of skull, the middle cranial fossa had the majority involvement of $12(30.6 \%)$ (Table 11). Abrasion,

\begin{tabular}{|l|c|c|}
\hline Length of hospitalization & $\mathbf{n = 1 8}$ & Percentage victims \\
\hline$<24$ hours & 8 & 44.4 \\
\hline$>24$ hours to $<1$ week & 3 & 16.7 \\
\hline$>1$ week to $<1$ month & 2 & 11 \\
\hline$>1$ month to $<3$ months & 1 & 5.5 \\
\hline$>3$ months & 1 & 5.5 \\
\hline Discharged and readmitted & 3 & 16.7 \\
\hline
\end{tabular}

Table 7: Length of hospitalization prior to a road traffic death.

\begin{tabular}{|c|c|c|}
\hline Type of injuries & $n=102$ & Percentage victims \\
\hline Head & 67 & 65.7 \\
\hline Scalp injury & 53 & 79.1 \\
\hline Subscalpular haematomas & 26 & 38.8 \\
\hline Intracranial haemorrhages & 42 & 62.6 \\
\hline Extradural & 2 & 4.8 \\
\hline Subdural & 31 & 73.8 \\
\hline Subarachnoid & 36 & 85.7 \\
\hline Intracerebral & 2 & 4.8 \\
\hline Meninges torn & 5 & 7.5 \\
\hline Skull fractures & 39 & 58.2 \\
\hline No fractures & 28 & 41.8 \\
\hline Brain injury & 27 & 40.2 \\
\hline Thoracic injuries & 56 & 54.9 \\
\hline Haemothorax & 4 & 7.1 \\
\hline Clavicular and rib cage fracture & 51 & 91.1 \\
\hline Lungs & 14 & 25 \\
\hline Heart & 4 & 7.1 \\
\hline Mediastinum & 1 & 1.8 \\
\hline Abdominal injuries & 31 & 30.3 \\
\hline Haemoperitoneum & 16 & 51.6 \\
\hline Liver & 16 & 51.6 \\
\hline Spleen & 6 & 19.4 \\
\hline Kidney & 4 & 12.9 \\
\hline Pelvic bone fractures & 5 & 16.1 \\
\hline Multiple injuries & 57 & 55.6 \\
\hline Abrasion, contusion and laceration & 57 & 100 \\
\hline Limb fractures & 17 & 29.8 \\
\hline Traumatic/ Flaying injuries & 7 & 12.2 \\
\hline Vertebral injuries & 21 & 20.5 \\
\hline $\begin{array}{l}\text { Fracture/dislocation of the cervical } \\
\text { vertebra }\end{array}$ & 16 & 76.2 \\
\hline $\begin{array}{l}\text { Fracture/dislocation of the thoracic } \\
\text { vertebra }\end{array}$ & 5 & 23.8 \\
\hline Major vessel injuries & 12 & 11.7 \\
\hline Aorta & 10 & 83.3 \\
\hline Superior mesenteric artery & 2 & 16.6 \\
\hline
\end{tabular}

Table 8: Distribution of all injuries due to fatal road traffic accidents.

\begin{tabular}{|l|c|c|}
\hline & $\mathbf{n = 4 2}$ & Percentage victims \\
\hline Intracranial haemorrhage without fracture & 14 & 33.3 \\
\hline Intracranial haemorrhage with fracture & 28 & 66.6 \\
\hline
\end{tabular}

Table 9: Distribution of intracranial haemorrhage with or without fractures. 


\begin{tabular}{|l|c|c|}
\hline Type of fracture & $\mathbf{n = 3 9}$ & Percentage victims \\
\hline Depressed & 4 & 10.3 \\
\hline Comminuted & 18 & 46.2 \\
\hline Diastatic & 5 & 12.8 \\
\hline Linear & 15 & 38.4 \\
\hline Ringed (Foreman magnum) & 2 & 5.1 \\
\hline Base of skull & 15 & 38.4 \\
\hline
\end{tabular}

Table 10: Distribution of the type of skull fractures.

\begin{tabular}{|l|c|c|}
\hline Skull bones fractured & $\mathbf{n = 3 9}$ & Percentage victims \\
\hline Frontal & 16 & 41 \\
\hline Parietal & 10 & 25.6 \\
\hline Temporal & 20 & 51.2 \\
\hline Occiput & 7 & 17.9 \\
\hline Sphenoid & 8 & 20.5 \\
\hline Ethmoid & 6 & 15.3 \\
\hline Anterior cranial fossa & 3 & 7.6 \\
\hline Middle cranial fossa & 12 & 30.6 \\
\hline Posterior cranial fossa & 0 & 0 \\
\hline Mandible & 6 & 15.3 \\
\hline Maxillary & 7 & 17.9 \\
\hline
\end{tabular}

Table 11: Distribution of the skull bones fractured.

\begin{tabular}{|l|c|c|}
\hline Road user & $\mathbf{n = 1 0 2}$ & Percentage victims \\
\hline Passenger & 10 & 83.3 \\
\hline Driver & 1 & 8.3 \\
\hline Pedestrian & 1 & 8.3 \\
\hline
\end{tabular}

Table 12: Distribution of road user with major vessel injuries.

\begin{tabular}{|l|c|c|}
\hline Mechanism of death & $\mathbf{n = 1 0 2}$ & Percentage victims \\
\hline Haemorrhagic shock & 90 & 88.2 \\
\hline Septic shock & 2 & 1.9 \\
\hline Asphyxia & 7 & 6.8 \\
\hline Arrhythmia & 3 & 2.9 \\
\hline
\end{tabular}

Table 13: Distribution of the mechanisms of death.

contusion and laceration of $57(100 \%)$ was seen with all multiple injuries followed by limb fractures of 17 (29.8\%) and traumatic/flaying injuries of 7 (12.2\%). Clavicular and rib cage fractures of $51(91.1 \%)$ and lung injuries of $14(25 \%)$ were the most numerous of the thoracic injuries whilst haemoperitoneum and liver injuries of 16 (51.6\%) respectively were for the abdominal injuries.

Aortic transection was most common of 10 (83.3\%) with the only major vessel involved was the superior mesenteric artery transection of $2(16.6 \%)$ (Table 8$)$. Also to note that for all major vessel injuries there were 10 passengers, 1 pedestrian and 1 driver involved (Table 12). Furthermore, out of the 10 passengers 3 were restrained by seat belts while the restrain status of the other passengers was unknown. The most common mechanism of death was haemorrhagic shock of 90 (88.2\%) followed by asphyxia of 7 (6.8\%), arrhythmias of 3 (2.9\%) and finally septic shock of 2 (1.9\%) (Table 13$)$.

\section{Discussion}

RTA produce disabilities, absenteeism and fatalities that lead to loss of productivity, increase in cost, increased financial borrowing, increased debt and decreased food consumption [1]. Fiji's estimated road traffic death rate is 4.4 times lower than that of a country of similar demographic profile like Guyana. In this study males constituted $70.5 \%$ while females were $29.5 \%$. In Fiji, males are the majority breadwinners

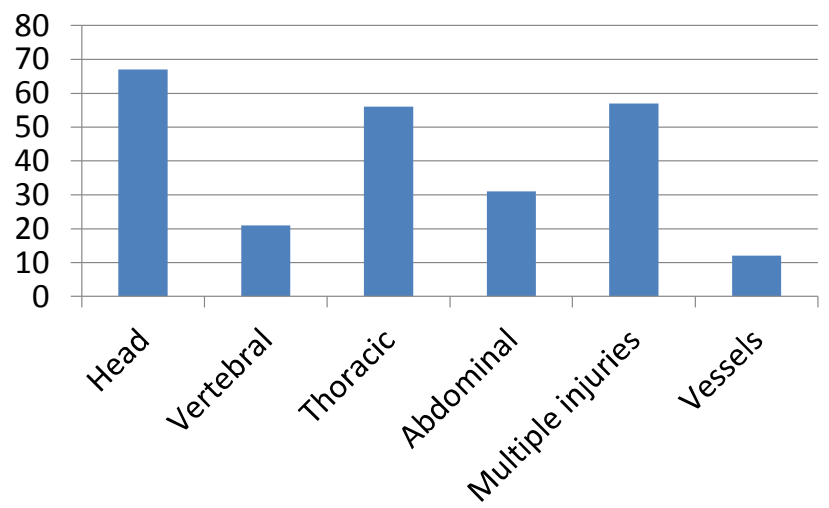

Figure 4: Distribution of injuries according to body regions injured.

and more often exposed to out of the household movement, therefore explaining the increased males involved in fatal RTA. This has been seen by many other researches [8-13].

The highest road traffic deaths according to age groups were from 15 to 44 years $(51.9 \%)$ and this was generally similar to studies in other countries [8-17]. This age bracket is the most socially, economically and physically dynamic period of life of an individual and are found frequently outdoors. Therefore, they are a high risk group and awareness on road safety should be focused at this age group.

The two main ethnic groups of iTaukei and Fijians of Indian descent were the most frequent to succumb (96\%) to fatal road traffic accidents. Proportionally this correlates with the overall population ethnic group standing.

The Western $(50.9 \%)$ and Central $(40.1 \%)$ divisions are located on the main island of Viti Levu and having $70 \%$ of Fiji's population [6]. These divisions had the most road traffic deaths due to the high population [6] and for being the most dynamic divisions. The western side of Fiji is the largest with the tourism and sugar industry whilst the central division houses the capital city and executive parts of business, institutions, government departments etc.

Upon analysis, majority of fatal RTA (40.1\%) occurred on semiurban roads and followed by those occurring on the highway (25.4\%) and rural roads $(22.5 \%)$. This is due to the increase in the urban and suburban population due to rapid urbanization.

In this study the commonest type of road user were the vehicular occupants (67.5\%) who included passengers (51.9\%) and drivers (15.6\%). Generally pedestrians have the highest numbers of road traffic deaths but not in this study that has similar findings to that of another report [18-20]. When considering all vehicular disruptive collision types $(69.5 \%)$, it is clear that more emphasis of passenger preparedness and the enforcement of the national passenger and driver related laws need to be greatly improved, since current enforcement ratings stand accordingly at 2 to 6 out of 10 for Fiji [7].

The remaining collision types were related to pedestrians (30.5\%) and matched up with the second commonest type of road user, the pedestrian (31.2\%). This highlights the need for effective promotion of traffic rules education and the provision more sidewalk particularly outside of the urban centers.

Human behavioral error or factors $(93.1 \%)$ by all road users in this study was the most recorded causing fatal road traffic deaths. 
Examples include alcohol intoxication, speeding, distractive habits like using mobiles or managing the car radio etc. and sleep deprivation for drivers [21-25], poor awareness and preparedness for pedestrians and passengers.

This study period showed highest number of fatal road traffic accidents occurring in the months of October in 2011 (8.8\%) and August in 2012 (11.6\%). In Fiji, the last quarter of the year sees the beginning of festive season and vacation period.

Pre-hospital mortality was the highest in this study particularly road traffic death at the scene $(51.9 \%)$ and those whilst en route to hospital $(29.4 \%)$. This is a common observation by different researchers [22,23]. Also with reference to the type of roads where fatal road accidents occur, this study showed semi-urban (40.1\%), highway (25.4\%) and rural $(23 \%)$ areas were the commonest and farthest from the reach of prompt mobile medical consult and proper paramedic ambulance transfer. Considering that only $10 \%$ of all post-crash seriously injured are transported by ambulances [7] and the road traffic accidents occurring farthest from proper mobile medical treatment explains the increase in the high pre-hospital mortality in Fiji.

Regarding hospital mortality, this study showed majority of these were within the first 24 hours $(44.4 \%)$ and the rest were within three months of hospitalization (33.3\%). There is a need for better systematic coordination between all levels of medical care inclusive of intensive care, radiology, physiotherapy etc. in response to the occurrence of a post-crash seriously injured individual.

The commonest injuries were head (65.7\%), followed by multiple injuries (55.6\%), thoracic injuries (54.9\%), vertebral injuries $(20.5 \%)$ and vessel injuries (11.7\%). This is also found in other countries research [26-28].

Regarding head injuries scalp injury (79.1\%) was most seen followed by intracranial haemorrhages (62.6\%), skull fracture $(58.2 \%)$ and brain injuries (40.2\%). Majority of intracranial haemorrhages were subarachnoid (85.7\%) and subdural (73.8\%). Remarkably $41.8 \%$ of all head injuries were without skull fractures and $33.3 \%$ of all intracranial haemorrhages were found without fractures. Therefore, treating physicians should bear in mind that the absence of skull fractures does not rule out the presence of intracranial haemorrhages and be sensitive to prompt radiological survey. In this study commonest type of skull fracture was comminuted (46.2\%) followed by linear and base of skull fractures (38.4\%) individually. In addition to this, the skull bones commonly fractured were the temporal $(51.2 \%)$, frontal $(41 \%)$, the middle cranial fossa (30.6\%) and parietal bone (25.6\%).

External body surface abrasion, contusion and laceration (100\%) were noted in all multiple injuries trailed by limb fractures $(29.8 \%)$ and traumatic/flaying injuries (12.2\%).

Clavicular and rib cage fractures (91.1\%) and lung injuries (25\%) were the most numerous of the thoracic injuries, consistent with a study from India [17], whilst haemoperitoneum and liver injuries (51.6\%) respectively were for the abdominal injuries.

Major vessel injuries (11.7\%) were found in more than a tenth of all injuries with only transection of the aorta (83.3\%) and superior mesenteric artery (16.6\%) noted in this study. Of all major vessel injuries there were 10 passengers, 1 pedestrian and 1 driver involved, with 3 of this 10 passengers noted to be restrained by seat belts while the restrain status of the other passengers was unknown.

Mechanisms of death are physiological and biochemical derangements that contribute to death of the individual and in this study the majority were haemorrhagic shock (88.2\%) followed by asphyxia (6.8\%), arrhythmias (2.9\%) and finally septic shock (1.9\%). This is similar to the other studies $[18,29,30]$ where haemorrhagic shock is due to multiple external and internal visceral organs. Therefore, in response to an oncoming fatal RTA case the receiving health care facility should be prepared to manage massive haemorrhages at all levels accordingly.

\section{Conclusion}

This study concludes the pre-hospital mortality was the highest and highlights the need to establish quality accessible pre-hospital or mobile trauma care services particularly since most of fatal RTA occur in semiurban roads. This study also showed predominance and significance of head injuries due to fatal RTA with a third of all intracranial haemorrhages presenting without fractures. Therefore, trauma management from scene of accident to the emergency department and availability of good neurosurgical care inclusive of radiological support is essential for these patients. There is need to strengthen the involvement of the National Blood Service to complement the management of commonest mechanism of death in fatal RTA, that is haemorrhagic shock.

Also this study it has been observed that the human behavioural error or factors are mainly responsible for fatal RTA in Fiji. The high risk age bracket was 15 to 44 years with passengers being the highest road traffic deaths. The road safety and traffic rules awareness at all levels of society should be strengthened and directed at the high risk groups with more emphasis placed on the human errors and enforcement of current national traffic laws.

In this study pedestrians formed a third of all fatal RTA victims and this points out a need for more semi-urban pedestrian pathway clearing and sidewalk creation.

Also a proper national traffic traumatic injury surveillance registry is seriously required to reveal the contributing factors, circumstances and sequence of events leading to the RTA. This will be profitable to strengthen traffic law enforcement, fortify policy making to reduce the road carnage and improve trauma management at the national level in Fiji.

\section{References}

1. WHO Road traffic injuries. (http://www.who.int/mediacentre/factsheets/ fs358/ en/index.html)

2. "Motor vehicle deaths by country", GECD Health Data 2002. Retrieved from http://www.NationMaster.com/red/graph/hea_mot_veh_dea-health-motorvehicle-deaths\&b_printable $=1$.

3. Söderlund N, Zwi AB (1995) Traffic-related mortality in industrialized and less developed countries. Bull World Health Organ 73: 175-182.

4. anthro.palomar.edu/medical/med_3.html.

5. http://data.worldbank.org/country/fiji.

6. Fiji Islands Bureau of Statistics: 2007 Census of Population Data. (http://www. statsfiji.gov.fj).

7. WHO Global status report on road safety 2013: supporting a decade of action (http://www.who.int/violence_injury_prevention/road_safety_status/2013).

8. Kumar A, Lalwani S, Agrawal D, Rautji R, Dogra TD. Fatal road traffic accidents and their relationship with head injuries: An epidemiological survey of five years. The Indian Journal of Neurotrauma. Vol. 9, Issue 2, Pages 156-157, DOI: 10.1016/j.jint.2012.10.002

9. Salgado MS, Colombage SM (1988) Analysis of fatalities in road accidents Forensic Sci Int 36: 91-96.

10. Sahdev P, Lacqua MJ, Singh B, Dogra TD (1994) Road traffic fatalities in Delhi: 
Citation: Kalougivaki JJVP, Goundar RPS (2014) Retrospective Autopsy Based Study of Fatal Road Traffic Accidents in Fiji. J Forensic Res 5: 243 doi:10.4172/2157-7145.1000243

Page 6 of 6

causes, injury patterns, and incidence of preventable deaths. Accid Anal Prev 26: $377-384$.

11. Friedman Z, Kugel C, Hiss J, Marganit B, Stein M, et al. (1996) The Abbreviated Injury Scale. A valuable tool for forensic documentation of trauma. Am J Forensic Med Pathol 17: 233-238.

12. Sharma BR, Harish D, Sharma V, Vij K (2001) Road-traffic accidents--a demographic and topographic analysis. Med Sci Law 41: 266-274

13. Jha N, Agrawal CS (2004) Epidemiological Study of Road Traffic Accident Cases: A Study from Eastern Nepal. Regional Health Forum WHO South-East Asia Region, 8: 15-22.

14. Malhotra C, Singh MM, Garg S, Malhotra R, Dhaon BK, et al. (2005) Pattern And Severity Of Injuries In Victims Of Road Traffic Crashes Attending A Tertiary Care Hospital Of Delhi Anil Aggrawal's Internet Journal of Forensic Medicine and Toxicology 6: 2

15. Meel BL (2007) Trends in fatal motor vehicle accidents in Transkei region of South Africa. Med Sci Law 47: 64-68.

16. Wong ZH, Chong CK, Tai BC, Lau G (2009) A review of fatal road traffic accidents in Singapore from 2000 to 2004. Ann Acad Med Singapore 38: 594596.

17. Kumar SB, Tanuj K, Ritesh GM, Shankar MB, Vinod CN, et al. (2012) Victim Profile and Pattern of Thoraco-Abdominal Injuries ustained in Fatal Road Traffic Accidents. J Indian Acad Forensic Med 34: 17-20.

18. Shruthi P, Venkatesh VT, Viswakanth B, Ramesh B, Sujatha PL (2013) Dominic IR. Analysis of Fatal Road Traffic Accidents in a Metropolitan City of South India. J Indian Acad Forensic Med 35: 4

19. Centers for Disease Control and Prevention (CDC) (2004) Medical expenditures attributable to injuries--United States, 2000. MMWR Morb Mortal Wkly Rep 53 : $1-4$.

\section{Reported Road Casualties in Great Britain: 2010 Annual Report.}

21. Mirza FH, Hassan Q, Jajja N (2013) An autopsy-based study of death due to road traffic accidents in metropolis of Karachi. J Pak Med Assoc 63: 156-160.

22. Menon A, Pai VK, Rajeev A (2008) Pattern of fatal head injuries due to vehicular accidents in Mangalore. J Forensic Leg Med 15: 75-77.

23. Farooqui JM, Chavan KD, Bangal RS, Syed MM, Thacker PJ, et al. (2013) Pattern of injury in fatal road traffic accidents in a rural area of western Maharashtra, India. Australas Med J 6: 476-482.

24. Bener HR. Burgut H. Sidahmed R. AlBuz R. Sanya WA Khan (2009) Californian Journal of Health Promotion 7: 92-101.

25. Herman J, Ameratunga S, Wainiqolo I, Kafoa B, Robinson E, et al. (2012) The role of driver sleepiness in motor vehicle crash injuries in Fiji. Australasian Road Safety Research, Policing and Education Conference 4-6.

26. Montazeri A (2004) Road-traffic-related mortality in Iran: a descriptive study. Public Health 118: 110-113.

27. Friedman R, Harris JP, Sitzer M, Schaff HB, Marshall L, et al. (1988) Injuries related to all-terrain vehicular accidents: a closer look at head and neck trauma. Laryngoscope 98: 1251-1254.

28. Kumar A, Lalwani S, Agrawal D, Rautji R, Dogra TD (2008) Fatal road traffic accidents and their relationship with head injuries: An epidemiological survey of five years. IJNT 5: 63-67.

29. Kumar PM, Ziya A, Prashant A, Sudhir Y, Rajesh C, et al. (2006) Fatality Due to Chest Injury in Road Traffic Accident Victims of Varanasi and Adjoining Districts, U.P. Indmedica Medico-Legal Update 6: 3.

30. Kool B, Raj N, Wainiqolo I, Kafoa B, McCaig E, et al. (2012) Hospitalised and fatal head injuries in Viti Levu, Fiji: findings from an island-wide trauma registry (TRIP 4). Neuroepidemiology 38: 179-185. 